zation of the LRC-its evolution, organization, and operation. There is no singular heuristic LRC model since local conditions and service philosophies differ for each institution. Many of the service components, however, can be applied or modified to fit a particular situation.

Numerous organizational charts of existing programs are included. The difference between them underscores the uniqueness of the environment of which each is a part. An underlying current of the book is functionalism through humanism. Some insight into the LRC as a process can be gleaned from the notion that it should be humanistically oriented and not strictly goal centered. Public service and user accessibility are keynotes, and systematic planning and intelligent decision making, according to the authors, are a significant part of the process and underlie good service.

Instructional technology services, instructional development, and faculty development are also included with definitions for each. These discussions seem simplistic in the assessment of these fields; nonetheless, they provide a good overview. MBO for LRCs is also discussed with a brief procedure for its implementation. MBO (management by objectives) is a complex technique, and it would be difficult to apply its principles or even understand its value or potential use from this brief treatment. The concluding section explains various personnel and budgeting considerations, and a synopsis of their workings and interrelationships is included.

These books are good introductory assessments of the current status of college learning resource centers. The books manage to provide a good blend of theory and practicality. The success of the Bock and La Jeunesse book is predicated on doing what it purports to do; that is, it offers an overview of program planning. The Burlingame book is comprehensive in scope and is clearly written. In view of subject coverage and price they both should be recommended for professional reading and reference.-William A. McIntyre, New Hampshire Vocational-Technical College, Nashua.

Washington University. School of Medicine Library. Archives Procedural Manual. 2d ed. rev. St. Louis: Washington University
School of Medicine Library, 1978. 143p. $\$ 7.25$. ISBN 0-912260-08-4. (Available from Archives Section, Washington University School of Medicine Library, 4580 Scott Ave., St. Louis, MO 63110.)

The Archives Procedural Manual of Washington University's School of Medicine Library consists of 143 pages, printed on only one side and bound with one of those awkward plastic loose-leaf binders, and includes twenty flow charts and eighteen forms devoted to archives, manuscripts, microfilming, and oral history. A little more than half is devoted to the microfilmed (all collections, now totaling nearly forty, are apparently microfilmed after processing) and computer-indexed oral history programs.

This manual shares a common fault with many other library and archival procedure manuals. The emphasis is necessarily on the documentation of trivial steps in the process, the filling out of forms and the completion of procedures in the proper order. Slighted is the intellectual activity that marks the heart of the process, in part because it is not amenable to flowcharts and forms. Because of this, it would be a mistake to expect a procedures manual to teach a novice how to process a manuscript or archival group.

Nevertheless, an understanding of the theory basic to the process is a necessary component-one that is lacking here. For instance, a flowchart, after the importance of provenance and original order has been cited, directs the processor to divide the material into "subgroups" based on formats. In addition, the processing of loose papers, "subgroup \#3," indicates that they are to be specifically described at the item level in the inventory. This is particularly ironic, considering the claim that it is the general applicability of this manual that caused it to be published.

While nearly every page in this manual is dated August 1, 1978, indicating that it is a current revision, archaic practices and principles abound. For a nonarchival example of a living fossil, see the job descriptions in which the archivist, a "he," supervises the archives library assistant II, a "she," as well as the "microfilm camera operator in her work." Most of the reportedly twelve hundred purchasers of the first edition will probably not need this second edition; the preface indicates that the only major change has been the addi- 


\section{Special Report:}
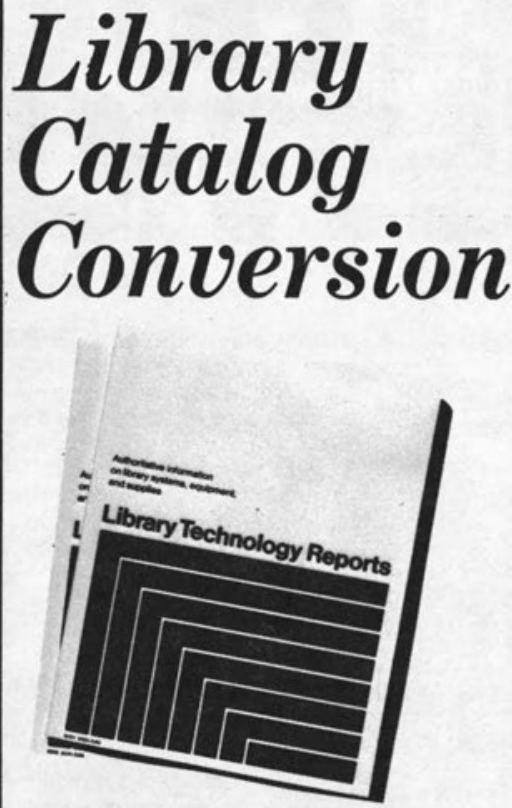

The key to library automation is the conversion of the card catalog to machine-readable form. This conversion process can involve the commitment of many thousands of dollars of the library's budget-not only in the current year, but in years to come, since decisions which are made initially can have far-reaching consequences.

The March/April 1978 issue of Library Technology Reports contains a full-length report on the costs, problems, strategies, and techniques of conversion by Brett Butler, Brian Aveney, and William Scholz.

March/April 1978 issue . . .\$40 Annual subscription (6 issues) . . . . . . . \$125

\section{Library Technology Reports}

American Library Association

50 East Huron Street

Chicago, Illinois 60611 tion of the oral history program and the deletion of the section on rare books. Examination reveals that few of the reviewers' criticisms (in American Archivist [July 1974] and College b Research Libraries [Sept. 1974]) have been addressed by this revision.-Terry Abraham, Washington State University, Pullman.

\section{Cameron, William J. Bibliographical Control} of Early Books. Sarada Ranganathan Endowment for Library Science Series 10. Sarada Ranganathan Lectures, 10, 1976. Bangalore: Sarada Ranganathan Endowment for Library Science, 1978. 78p. \$6.50.

In this series of five lectures, William Cameron, director of the Hand Printed Books Project and dean of the School of Library and Information Science, University of Western Ontario, develops his theory of bibliography and illustrates his argument with descriptions of several bibliographic searches.

The argument is the more significant aspect of the lecture series, but the descriptions of bibliographic searches compose the more striking and memorable and enjoyable aspect of the series. The descriptions include, for example, a quest for works printed by $\mathbf{H}$. Hills, Jr., and a second quest for data about eighteenth-century coffeehouse libraries. They will confirm many beginning librarians in their decision to become rare-book librarians.

The argument, in brief, is that the usable substitutes for a single universal bibliography compose a complex pattern of separate listings (resembling the picture side of a jigsaw puzzle). The author asserts (p.13) that these listings fulfill two conceptually distinct functions, namely: (1) lists of "neutrally descriptive items within objectively definable limitations"; and (2) control devices that "optimize the exercise of the appraisal powers of potential users or their agents."

But Cameron demonstrates in the subsequent discussion that, at least when machine-readable files are considered, it is convenient to redefine the first function as two functions.

A secondary but significant strain in the author's argument is the fact that humanistic scholars need access to publications in terms of selective criteria that are not well described in terms of ordinary subject bibliography. They often, for example, need to see lists of publica- 